\title{
Does it make difference to measure diaphragm function with $M$ mode (MM) or B mode (BM)?
}

\author{
Burhan Sami Kalın ${ }^{1,2}$ [D $\cdot$ Gül Gürsel ${ }^{2}$ (i)
}

Received: 13 June 2019 / Accepted: 25 November 2019 / Published online: 28 November 2019

(c) Springer Nature B.V. 2019

\begin{abstract}
Diaphragm dysfunction occurs in mechanically ventilated subjects. Recent literature suggests that diaphragm thickening fraction (DTF) measured by ultrasound can be useful to predict weaning outcome. However, there is no standardized approach in the measurement of diaphragm thickness (DT) and limited data exists comparing different measurement techniques of diaphragm thickness (M mode-MM or B mode-BM). The goal of this study was to compare MM with BM in the measurements of DT and excursion in the ICU subjects. DT measurements were obtained from the right diaphragm during tidal and maximal inspiratory breathing. Three measurements of the DT were taken both in MM and BM and their mean values were calculated. DT was measured during inspiration and expiration and DTF was calculated. Excursion of diaphragm was also measured with MM and BM during tidal and maximal inspiratory breathing. Bias and agreement between the two measurement methods were evaluated with Bland and Altman test. Sixty-two subjects were enrolled in the study. While 25 (40\%) subjects were receiving invasive mechanical ventilation, 14 (23\%) subjects ventilated noninvasively. There were no significant difference between the measurement results of $\mathrm{MM}$ and $\mathrm{BM}$. BM and $\mathrm{MM}$ tidal diaphragm measurements during the inspiratory $(0.3 \pm 0.08$ and $0.31 \pm 0.08 \mathrm{~cm} ; \mathrm{P}=0.022)$, expiratory $(0.24 \pm 0.07$ and $0.24 \pm 0.07 \mathrm{~cm} ; \mathrm{P}=0.315)$ phases and tidal DTF were $(27 \pm 16$ and $31 \pm 14 \%, \mathrm{P}=0.089)$ respectively. Results of our study suggests that except tidal inspiratory diaphragm thickness, all thickness and excursion measurements with MM and BM are very compatible with each other. Further studies are necessarry to confirm our results and to standardize the measurements of diaphragm.
\end{abstract}

Keywords Diaphragm ultrasound · Point of care ultrasound (POCUS) · Intensive care unit (ICU) · Respiratory failure · Mechanical ventilation

\section{Introduction}

Diaphragm is the main muscle of breathing and assessment of its thickness and excursion are important in detecting dysfunction and exhaustion [1]. Diaphragm dysfunction (DD) is associated with respiratory insufficiency and poor outcomes

This study was presented at ISICEM 2018-38th International Symposium on Intensive Care and Emergency Medicine.

Burhan Sami Kalın

bskalin@windowslive.com

Gül Gürsel

gurselg1@gmail.com

1 Division of Critical Care, Department of Internal Medicine, Gazi University School of Medicine, Ankara, Turkey

2 Department of Pulmonary Critical Care Medicine, Gazi University School of Medicine, 06560 Ankara, Turkey
[2]. Clinical trials in the last decade have drawn attention to the relationship between DD and mechanical ventilation in intensive care unit (ICU) subjects. They have shown that most frequent cause of DD acquired in ICU is invasive mechanical ventilation [3]. DD is a very common condition, causing to prolonged mechanical ventilation and longer stay in ICU. Clinically significant DD is observed nearly $60-80 \%$ of mechanically ventilated subjects [4]. Decrement in diaphragm muscle mass and contractility are reported in previous studies even in as early as $48 \mathrm{~h}$ after starting mechanical ventilation [5, 6]. DD has different definitions according to ultrasonographic measurements of diaphragm such as diaphragmatic thickening fraction (DTF) of less than 20-30\% during tidal breathing and a diaphragmatic excursion less than $10 \mathrm{~mm}$ from end-expiration to end-inspiration [7].

Functional status of diaphragm can be assessed by various methods such as chest radiography, fluoroscopy, pulmonary function test, electromyography and magnetic 
phrenic nerve stimulation [8]. Among them ultrasonography (US) is preferred recently because it is easy to perform, cost effective, non-radiating, non-invasive bedside tool for assessment of diaphragm function [9]. Recent findings suggest that diaphragm dysfunction is related with weaning failure and is associated with worse prognosis at the time of liberation from mechanical ventilation $[4,10,11]$. On the other hand despite these developments, the measurement method and cut off values for diaphragm dysfunction are not standardized yet. For example, it is not certain that should we use diaphragm thickness, diaphragm thickening fraction or diaphragm excursion as the criterion of DD. In addition, in some studies, while measurements related to the diaphragm during weaning period are made when the subject is connected to the ventilator, in other studies it is done during spontaneous breathing trial. Lastly there is no certainity that measurements should be made with $\mathrm{M}$ Mode (MM) or B Mode (BM). Previous inferior vena cava (IVC) studies showed that, translational changes during the respiration negatively affect the maximum and minimum dimensions of the IVC, and with respiratory motion IVC can be displaced under the probe and measured outside the area where the diameter values should be measured [12]. The similar problem may also happens during diaphragm measurements. Diaphragm function can be evaluated by diaphragm thickness, thickening fraction and excursion, and these parameters can be measured with both MM or BM. In previous studies both mode were used widely [13-16]. The diaphragm moves in the caudal direction relative to the probe during inspiration and especially in MM, this movement may cause that the diaphragm thickness or excursion to be measured at different locations during inspirium and expirium.

The aim of this study is to investigate whether the measurements of diaphragm thickness, thickening fraction and excursion influenced by use of MM or BM.

\section{Methods}

\subsection{Study population, data collection and measurements}

This observational study was carried out at Gazi University School of Medicine, Department of Pulmonary Critical Care Medicine. The study protocol was approved by the ethics committee of our institution (28.12.2015/166). Sixty-two subjects age $\geq 18$ years old who were consecutively admitted to the ICU were included in the study. The inclusion criteria were stable hemodynamic status, no administration of sedative agents or neuromuscular blocking agents $>24 \mathrm{~h}$ before enrollment and ability to sustain pressure support ventilation for at least $15 \mathrm{~min}$. The exclusion criteria were the presence of pneumothorax, pregnancy, anatomical malformation of the diaphragm a history of either neuromuscular disease or thoracic surgery and poor image quality. Subject's age, diagnosis, comorbidities, duration of mechanical ventilation, length of ICU and hospital stay, acute physiology and chronic health evaluation (APACHE II) score on admission, Body Mass Index (BMI), arterial blood gas analysis parameters and Glascow Coma Scale (GCS) were recorded. Diaphragm measurements were performed during the first week of ICU stay in 50 subjects. In seven intubated and 5 non-intubated subjects measurements were performed 7 days after ICU admission. Pressure support mode was used during the study period and was set in order to provide a tidal volume of 6-8 $\mathrm{ml} / \mathrm{kg}$ of ideal body weight, without any sign of respiratory distress or discomfort. End-expiratory pressure was set as $5 \mathrm{~cm} \mathrm{H}_{2} \mathrm{O}$. Measurements were performed while subjects were in semi-recumbent position and were not receiving sedation or neuromuscular blocking agents. A standart ultrasound machine, Vivid-Q (GE Healthcare), was used for ultrasonographic evaluations with a linear probe (7.5-10 MHz) and a low-frequency $(1-5 \mathrm{MHz})$ sector probe. In general, the liver provides an excellent ultrasound window, so that the right side gives better view than the left side. Therefore all measurements were performed on the right side. All researchers who applied ultrasonographic measurements were experienced in diaphragm USG (GG has 4 years experience with more than 300 diaphragm examination and BSK has 2 years experience with about 150 examination). For the measurement of DT, diaphragm was visualized by placing the transducer perpendicular to the chest wall in the eighth or ninth intercostal space, between the anterior axillary and the midaxillary lines, to observe the zone of apposition (ZOA). For evaluation of diaphragmatic excursion, the probe was placed below the right subcostal margin in the mid-clavicular line. BM and MM were then used to display diaphragm excursion and three subsequent measurements were recorded. Measurement of diaphragm excursion were made according to technic described by Skaarub et al. [17]. Several images of the diaphragm were captured and stored, including at least three at the point of maximum thickening at maximum inspiratory level and than resting tidal volume. Both BM and MM images were recorded for thickening and excursion measurements. Paradoxical motion was defined as diaphragm moving away from the transducer (with MM) during inspiration. Measurements were performed by the two intensivist. To measure DT with MM and BM, the same screen was used (Fig. 4). When BM and MM images are seen on the same screen, expiratory diaphragm thickness was measured by both BM and MM. Inspiratory and expiratory measurements of thickness were performed carefully at the same part of the diaphragm. MM measurements were performed on the MM screen and thin part was measured as expiratory thickness and thick part was measured as 
inspiratory thickness. Physicians were blinded to measure of each other. To determine inter-observer reliability, each physician evaluated previously recorded three consecutive MM and BM measurements of tidal expiratory thickness and tidal excursion in 15 subjects. Their means were calculated and used in the ICC analysis. The DTF was calculated as percentage from the following formula: Thickness at peak inspiration - Thickness at end expiration/Thickness at end expiration $\times 100$ [5]. In addition to these analysis we compared DD rates according to $\mathrm{BM}$ and $\mathrm{MM}$ measurements of the diaphragm. Our DD definition was that: existance of at least 2 of the following 3 criteria; Tidal expiratory diaphragm thickness $<2 \mathrm{~mm}$, tidal diaphragm excursion $<10 \mathrm{~mm}$ and tidal DTF $<20 \%$ [7].

\subsection{Statistical analysis}

We used SPSS software (version 22.0) to carry out statistical analyses. Continuous variables were described as mean \pm standard deviation or median (interquartile range) depending on whether distribution was normal or not. Data distribution was analyzed using a Kolmogorov-Smirnov test. $\mathrm{P}$ values lower than 0.05 were considered as statistically significant. The averages were compared with the Student's t test. We used Chi square test and Kappa statistic in order to compare DD rates according to BM and MM measurements. Pearson correlation coefficient was used for correlation coefficient calculations (r). Agreement and bias between the two measurement methods (MM and BM) for thickening and excursion measurements were evaluated with Bland and Altman test. Intra-class correlation coefficient (ICC) was used for the assessment of inter-observer reliability. ICC greater than 0.7 was taken to indicate a strong correlation. The evaluation was carried out with SPSS statistical programme.

\section{Results}

Table 1 shows the demographic characteristics of the subjects. Seventeen subjects (27\%) were female. Mean age was $68 \pm 17$ years. Twenty-five (40\%) subjects received invasive mechanical ventilation, 14 (23\%) subjects received noninvasive mechanical ventilation during the ICU stay. Three subjects had tracheostomy and 5(8\%) subjects had paradoxical breathing. During the MM measurements, the diaphragm moved and slided slightly away from the transducer during inspiration in nine subjects. The mean duration of mechanical ventilation was $23 \pm 26$ days, mean length of ICU stay was $20 \pm 23$ days and mean hospital stay was $25 \pm 24$ days. BM and MM tidal diaphragm measurements during the inspiratory $(0.3 \pm 0.08$ and $0.31 \pm 0.08 \mathrm{~cm}$; $\mathrm{P}=0.022)$, expiratory $(0.24 \pm 0.07$ and $0.24 \pm 0.07 \mathrm{~cm}$; $\mathrm{P}=0.315)$ phases and DTF were $(27 \pm 16$ and $31 \pm 14 \%$;
Table 1 Demographic characteristics of the subjects $(n=62)$

\begin{tabular}{ll}
\hline Age, years (mean $\pm \mathrm{SD})$ & $68 \pm 17$ \\
APACHE II Score $(\mathrm{mean} \pm \mathrm{SD})$ & $23 \pm 8$ \\
Body mass index, $\mathrm{kg} / \mathrm{m}^{2}(\mathrm{mean} \pm \mathrm{SD})$ & $25 \pm 6$ \\
Glasgow Coma Scale $($ mean $\pm \mathrm{SD})$ & $9 \pm 4$ \\
Sex: female, $\mathrm{n}(\%) /$ male, $\mathrm{n}(\%)$ & $17(27 \%) / 45(73 \%)$ \\
Arterial blood gas analysis, $\mathrm{n}($ mean $\pm \mathrm{SD})$ & \\
$\mathrm{pH}$ & $7.39 \pm 0.08$ \\
$\mathrm{PO} 2$, mmHg & $83 \pm 30$ \\
PCO2, mmHg & $44 \pm 16$ \\
HCO3, mEq & $25 \pm 7$ \\
SaO2, $\%$ & $93 \pm 8$ \\
Admission diagnosis, $\mathrm{n}(\%)$ & \\
COPD & $34(55 \%)$ \\
Sepsis & $24(39 \%)$ \\
Renal & $10(16 \%)$ \\
Pulmonary & $61(98 \%)$ \\
Cardiac & $7(11 \%)$ \\
Gastrointestinal & $1(1.6 \%)$ \\
Neurologic & $3(5 \%)$ \\
Rheumatologic & $1(1.6 \%)$ \\
ARDS & $4(7 \%)$ \\
Comorbidities, $\mathrm{n}(\%)$ & \\
Pulmonary & $45(73 \%)$ \\
Cardiac & $34(55 \%)$ \\
Gastrointestinal & $2(3 \%)$ \\
Neurological & $11(18 \%)$ \\
Endocrinological & $6(10 \%)$ \\
Malignancy & $12(20 \%)$ \\
Renal & $5(8 \%)$ \\
Rheumatologic & $1(1.6 \%)$ \\
Immunosuppression & $10(16 \%)$ \\
\hline
\end{tabular}

$n$ number, APACHE II acute physiologic and chronic health evaluation, $S D$ standard deviation, $I C U$ intensive care unit, $\mathrm{kg}$ kilogram, $\mathrm{m}^{2}$ square meter, COPD chronic obstructive pulmonary disease, ARDS acute respiratory distress syndrome

$\mathrm{P}=0.089$ ) respectively. $\mathrm{BM}$ and $\mathrm{MM}$ maximum inspiratory diaphragm measurements during the inspiratory phase $(0.33 \pm 0.08$ and $0.35 \pm 0.09 \mathrm{~cm} ; \mathrm{P}=0.167)$ and DTF were $(34 \pm 22$ and $34 \pm 22 \%, \mathrm{P}=0.983)$ respectively. $\mathrm{BM}$ and $\mathrm{MM}$ tidal diaphragm excursion measurements were $(1.3 \pm 0.8$ and $1.4 \pm 0.9 \mathrm{~cm} ; \mathrm{P}=0.369), \mathrm{BM}$ and $\mathrm{MM}$ maximum inspiratory diaphragm excursion measurements were $(1.8 \pm 1.3$ and $2.1 \pm 1.5 \mathrm{~cm} ; \mathrm{P}=0.195)$ respectively Table 2 . Table 3 summarizes the reference values of diaphragm thickness and excursion measured with BM and/or MM in the mechanically ventilated subjects and healthy volunteers in previously published studies. Despite existance of different degree diaphragm movements relative to the ultrasound transducer secondary to respiratory movement, there was no significant difference between the measurement results of MM and BM. 
Table 2 Measurements of diaphragm at maximum insiratory and tidal respiratory with B mode and M mode

\begin{tabular}{|c|c|c|c|c|c|}
\hline \multirow[t]{2}{*}{ Parameters } & \multirow[t]{2}{*}{ Paired t test } & \multicolumn{2}{|c|}{ Pearson correlation } & \multicolumn{2}{|l|}{ Bland-Altman } \\
\hline & & & & One sample agreement & $\begin{array}{l}\text { Lineer } \\
\text { regression } \\
\text { BIAS }\end{array}$ \\
\hline Tidal inspiratory thickness, $\mathrm{cm}$ (n:58) & $\mathrm{P}=0.022$ & $\mathrm{r}=0.79$ & $\mathrm{P}=0.0001$ & $\begin{array}{l}\text { Mean difference } \\
P=0.022 \\
-0.017 \pm 0.106\end{array}$ & $\begin{array}{l}\text { LR } \\
P=0.849\end{array}$ \\
\hline $\mathrm{BM}$ & $0.3 \pm 0.08$ & & & & \\
\hline MM & $0.31 \pm 0.08$ & & & & \\
\hline Tidal expiratory thickness, cm (n:57) & $P=0.315$ & $\mathrm{r}=0.86$ & $\mathrm{P}=0.0001$ & $\begin{array}{l}\text { Mean difference } \\
P=0.315 \\
-0.005 \pm 0.072\end{array}$ & $\begin{array}{l}\mathrm{LR} \\
\mathrm{P}=0.861\end{array}$ \\
\hline $\mathrm{BM}$ & $0.24 \pm 0.07$ & & & & \\
\hline MM & $0.24 \pm 0.07$ & & & & \\
\hline Maximum inspiratory thickness, $\mathrm{cm}(\mathrm{n}: 38)$ & $P=0.167$ & $\mathrm{r}=0.72$ & $\mathrm{P}=0.0001$ & $\begin{array}{l}\text { Mean difference } \\
P=0.167 \\
-0.015 \pm 0.123\end{array}$ & $\begin{array}{l}\mathrm{LR} \\
\mathrm{P}=0.553\end{array}$ \\
\hline $\mathrm{BM}$ & $0.33 \pm 0.08$ & & & & \\
\hline MM & $0.35 \pm 0.09$ & & & & \\
\hline Tidal TF, \% (n:57) & $P=0.089$ & $r=0.53$ & $\mathrm{P}=0.0001$ & $\begin{array}{l}\text { Mean difference } \\
P=0.089 \\
-3.35 \pm 28.7\end{array}$ & $\begin{array}{l}\text { LR } \\
P=0.441\end{array}$ \\
\hline $\mathrm{BM}$ & $27 \pm 16$ & & & & \\
\hline MM & $31 \pm 14$ & & & & \\
\hline Maximum inspiratory TF, \% (n:38) & $\mathrm{P}=0.983$ & $\mathrm{r}=0.42$ & $\mathrm{P}=0.008$ & $\begin{array}{l}\text { Mean difference } \\
\mathrm{P}=0.983 \\
0.08 \pm 46.25\end{array}$ & $\begin{array}{l}\mathrm{LR} \\
\mathrm{P}=0.811\end{array}$ \\
\hline $\mathrm{BM}$ & $34 \pm 22$ & & & & \\
\hline MM & $34 \pm 22$ & & & & \\
\hline Tidal diaphragmatic excursion, $\mathrm{cm}(\mathrm{n}: 28)$ & $P=0.369$ & $r=0.67$ & $\mathrm{P}=0.0001$ & $\begin{array}{l}\text { Mean difference } \\
\mathrm{P}=0.369 \\
-0.12 \pm 1.38\end{array}$ & $\begin{array}{l}\mathrm{LR} \\
\mathrm{P}=0.552\end{array}$ \\
\hline $\mathrm{BM}$ & $1.3 \pm 0.8$ & & & & \\
\hline MM & $1.4 \pm 0.9$ & & & & \\
\hline $\begin{array}{l}\text { Maximum inspiratory diaphragmatic excursion, } \\
\mathrm{cm}(\mathrm{n}: 21)\end{array}$ & $P=0.226$ & $r=0.80$ & $\mathrm{P}=0.0001$ & $\begin{array}{l}\text { Mean difference } \\
\mathrm{P}=0.226 \\
-0.24 \pm 0.88\end{array}$ & $\begin{array}{l}\mathrm{LR} \\
\mathrm{P}=0.260\end{array}$ \\
\hline $\mathrm{BM}$ & $1.8 \pm 1.3$ & & & & \\
\hline MM & $2.1 \pm 1.5$ & & & & \\
\hline
\end{tabular}

$n$ number, $B M \mathrm{~B}$ mode, $M M \mathrm{M}$ mode, $p$ probability, $r$ correlation coefficient, $L R$ linear regression, $T F$ thickening fraction, $c m$ centimeter

In general there was good agreement and no proportional bias between the measurements of 2 modes $(P>0.05)$. But there was not good agreement in the measurement of tidal inspiratory thickness.

When we compared DD rates according to $\mathrm{BM}$ and $\mathrm{MM}$ measurements of the diaphragm, there was no statistically significant difference between the DD rates across the modes' measurements. Rate of DD in the whole study group was $21 \%(11 / 52)$ and $8 \%(4 / 52)$ according to $\mathrm{BM}$ and $\mathrm{MM}$ measurements respectively $(\mathrm{P}=0.628)$. Kappa statistics was also showed no statistically significant disagreement across the modes $(\mathrm{P}=0.845)$.
Figure 1a-c show Bland-Altman graphics of tidal inspiratory thickness, maximum inspiratory thickness and tidal expiratory thickness, Fig. 2a and b show Bland-Altman graphics of tidal thickening fraction and maximum inspiratory thickening fraction, Fig. 3a and b show Bland-Altman graphics of tidal excursion and maximum inspiratory excursion, respectively. Figures $4 \mathrm{a}, \mathrm{b}$ and 5 show measurement methods of thickness and excursion via BM and MM, respectively. Table 3 summarizes the reference values of diaphragm thickness and excursion measured with BM and/ or MM in the mechanically ventilated subjects and healthy volunteers in previously published studies. In inter-observer 
Table 3 The reference values of diaphragm thickness and excursion in ultrasound assessment

\begin{tabular}{|c|c|c|c|c|}
\hline \multirow[t]{2}{*}{ Study of subgroup } & \multicolumn{2}{|l|}{ B-Mode } & \multicolumn{2}{|l|}{ M-Mode } \\
\hline & $\begin{array}{l}\text { Diaphragm } \\
\text { thickness (mm) }\end{array}$ & $\begin{array}{l}\text { Excursion } \\
(\mathrm{mm})\end{array}$ & $\begin{array}{l}\text { Diaphragm } \\
\text { thickness (mm) }\end{array}$ & Excursion $(\mathrm{mm})$ \\
\hline \multicolumn{5}{|l|}{ Healthy volunteers } \\
\hline Gottesman 1997 [36] & $2.7 \pm 0.5$ & & & \\
\hline Bousseges 2009 [37] & & & & $29 \pm 6$ \\
\hline Testa $2011[38]$ & & & & $18.4 \pm 7.6$ \\
\hline Voyvoda 2012 [39] & & & & $16(6-37)$ \\
\hline Vivier 2012 [25] & $2.6(2.1-3.0)$ & & & \\
\hline Carrillo-Esper 2016 [40] & $1.6 \pm 0.4$ & & & \\
\hline Laviola 2018 [41] & $2.5 \pm 0.4$ & & & \\
\hline Boussuges 2018 [15] & & & & $30 \pm 11$ \\
\hline Boccatonda 2019 [42] & & & & $15 \pm 6$ \\
\hline Zhu 2019 [43] & $1.6 \pm 0.4$ & & & $14.8 \pm 2.6$ \\
\hline Fayssoil 2019 [44] & & & $1.5(1.3-1.9)$ & $32(19-36)$ \\
\hline Spadaro 2019 [45] & & & & $16(12-18)$ \\
\hline \multicolumn{5}{|c|}{ Mechanically ventilated subjects } \\
\hline Schepens 2015 [46] & $1.9 \pm 0.4$ & & & \\
\hline Goligher 2015 [47] & & & $2.4 \pm 0.8$ & \\
\hline Yoo 2016 [48] & $2.8(2-3.5)$ & & & $16.9(10.6-19.6)$ \\
\hline Theerawit 2018 [49] & & & & $13.5 \pm 6.5$ \\
\hline Pirompanich 2018 [50] & $2.4 \pm 0.9$ & & & \\
\hline Vivier 2019 [51] & & & $2.5 \pm 1.1$ & $14 \pm 7$ \\
\hline Rittayamai 2019 [52] & & & & $24.9 \pm 8.4$ \\
\hline
\end{tabular}

$m m$ millimeter

reliability analysis of all the measurements, ICC coefficients were 0.96 for tidal expiratory thickness in BM, 0.96 for tidal expiratory thickness in MM, 0.95 for tidal diaphragmatic excursion in BM, 0.94 for tidal diaphragmatic excursion in $\mathrm{MM}$, respectively $(\mathrm{P}<0.05)$.

\section{Discussion}

In this study, our results showed that BM and MM measurements of expiratory thickness of diaphragm, maximum inspiratory thickness, tidal and maximum inspiratory DTF and excursion were significantly correlated, there were good agreement between each other and there was no bias among the measurements. There was no significant difference in the evaluation of DD incidence according to measurements with both modes. These results suggest that in the ICU subjects both BM and MM can be used to measure diaphragm. Only diaphragm thickness measured during tidal inspiration varied between MM and BM (disagreement) but bias was not detected between MM and BM measurements. However, the difference in tidal inspiration was too small to be clinically significant and it was not influenced the TF calculation results. Diaphragm BM or MM thickness evaluation is a feasible, reproducible and non-invasive technique to assess diaphragm activity and to evaluate the impact of mechanical ventilation on subject's diaphragm in terms of anatomical changes and muscle strength. When we examined the literature, we saw that both BM and MM was used to measure thickness and excursion of diaphragm. But, in the majority of diaphragm ultrasound studies diaphragm thickness measured by BM ultrasound imaging [18, 19]. MM is used more frequently to measure the excursion $[20,21]$. In our study, we determined the success rate of diaphragm imaging as $85 \%$ and this ratio was compatible with the literature [22].

We summarized ultrasound studies evaluating diaphragm dysfunction in Table 3. In these studies measurement of diaphragm thickness, thickening fraction and excursion were assessed with B mode and/or M mode. But we could not find any study specifically comparing MM with BM in thickness and excursion measurements.

In the Lerolle's study excursion during maximal inspiratory effort found to be well correlated with transdiaphragmatic pressures in subjects requiring prolonged mechanical ventilation after cardiac surgery and excursion of $<2.5 \mathrm{~cm}$ was a predictor of prolonged intubation [23]. Kim et al. was defined diaphragmatic dysfunction as tidal excursion of less than $10 \mathrm{~mm}$ or presence of diaphragmatic paradoxical movement. It has been emphasized that POCUS should be done in order to evaluate diaphragm dysfunction 


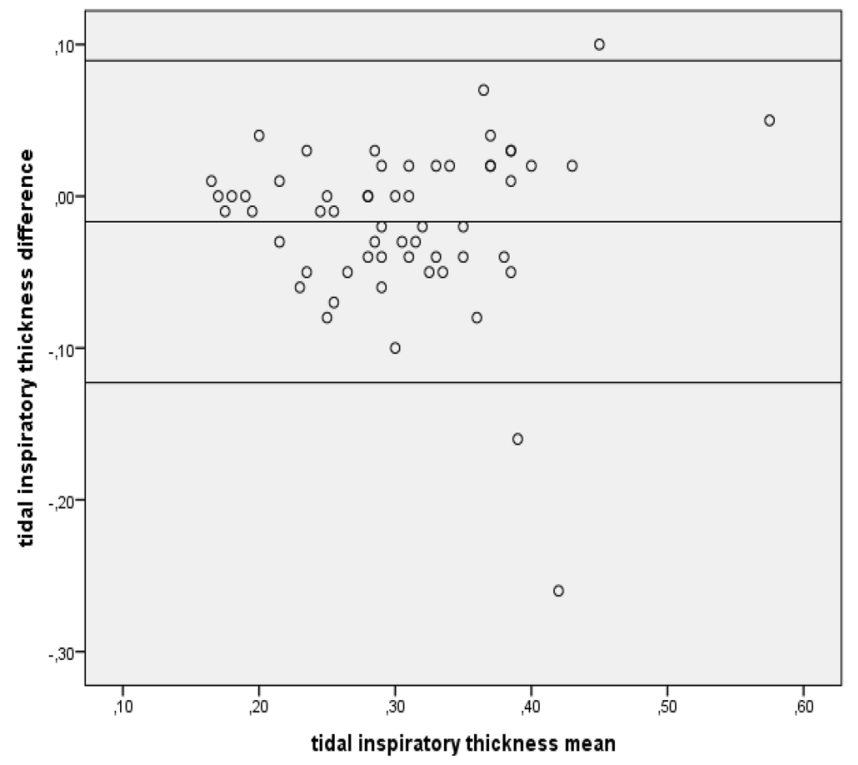

(a)

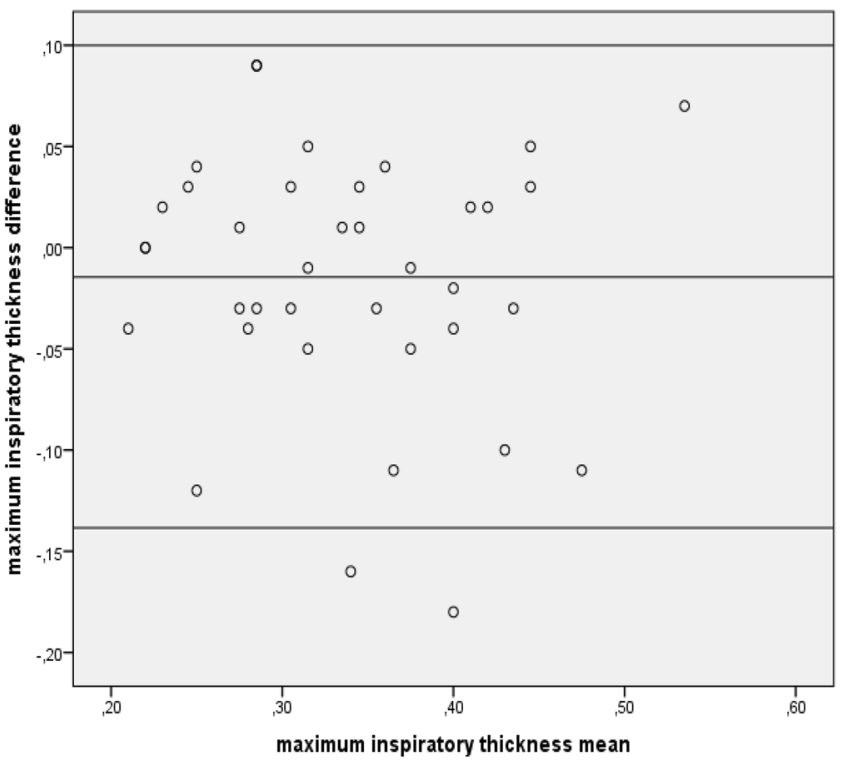

(b)

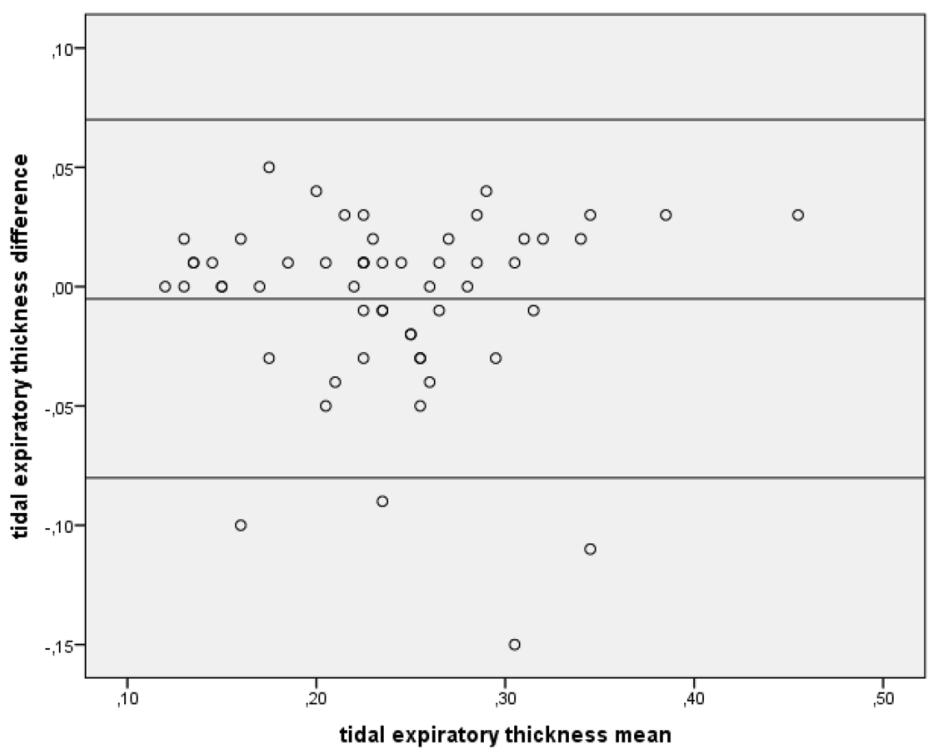

(c)

Fig. 1 a Bland-Altman graphics of tidal inspiratory thickness. b Bland-Altman graphics of maximum inspiratory thickness. c Bland-Altman graphics of tidal expiratory thickness

for difficult weaning [24]. Vivier et al. concluded that the use of MM ultrasonography to assess muscle function and contribution to respiratory burden is an useful, noninvasive and reproducible method [25]. Goligher et al., evaluated the feasibility, reproducibility and validity of diaphragm thickness measurements to assess inspiratory effort in mechanically ventilated subjects. They concluded that M-Mode technique may be employed to reliably detect diaphragmatic atrophy over time and to assess diaphragm contractile activity in ventilated subjects [26].

Some concerns about the diaphragm sonography have to be pointed out in clinical practice. Although M mode can be used to measure thickness and has the advantage of capturing multiple breaths within one image allowing for easier comparison, it has some limitations such as failure to visualize precise anatomy of diaphragm, wider variability 


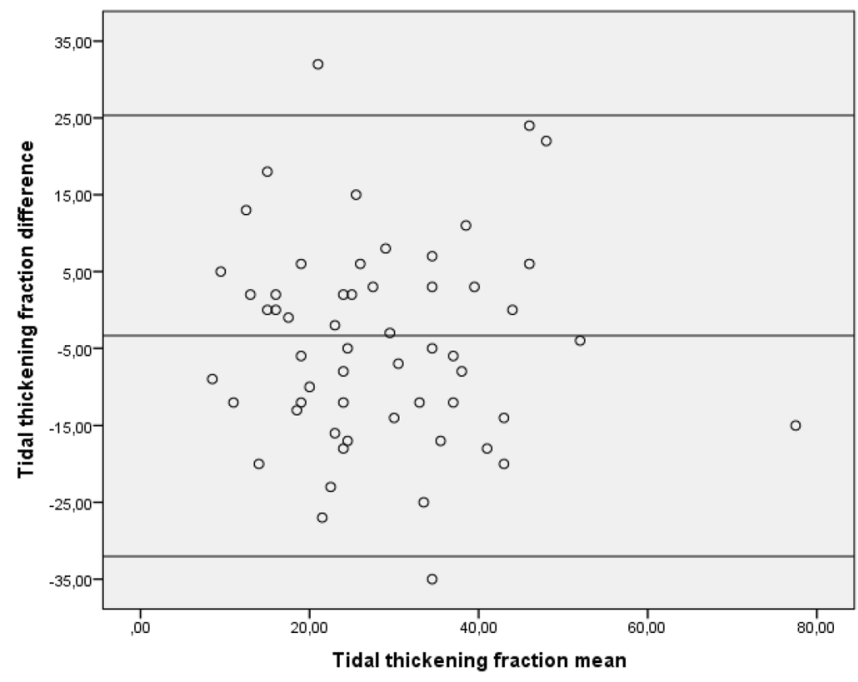

(a)

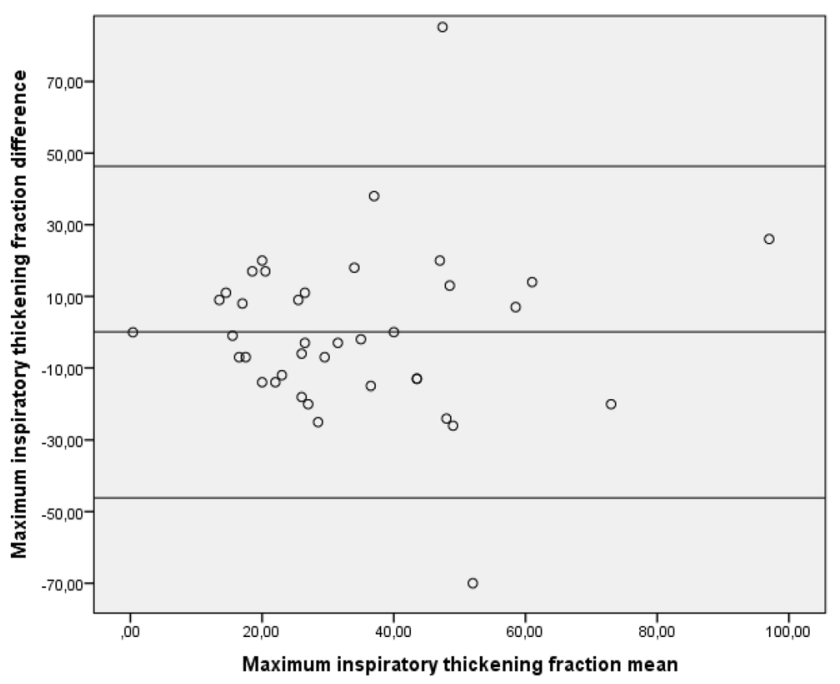

(b)

Fig. 2 a Bland-Altman graphics of tidal thickening fraction. b Bland-Altman graphics of maximum inspiratory thickening fraction

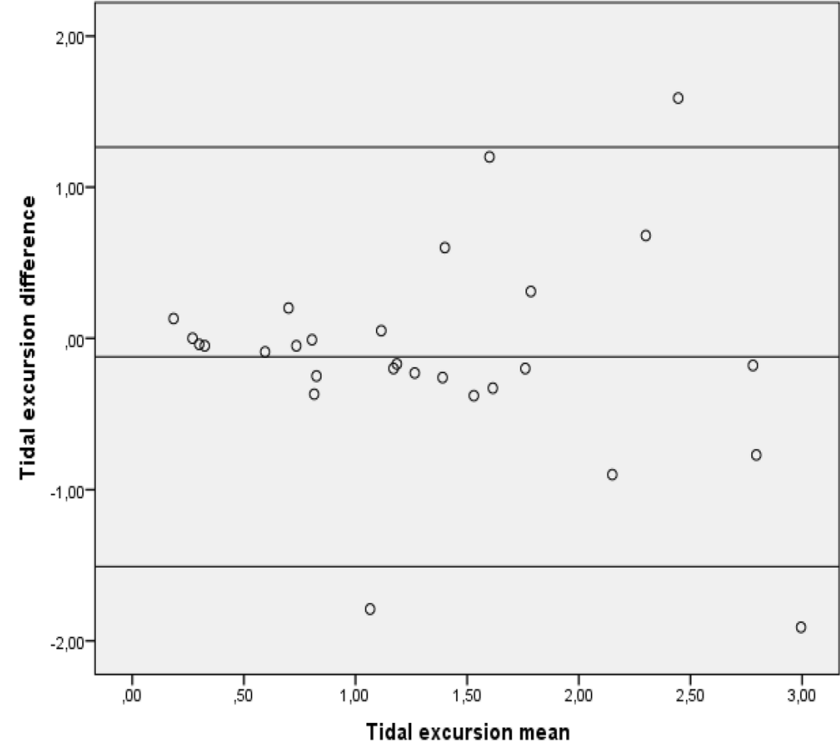

(a)

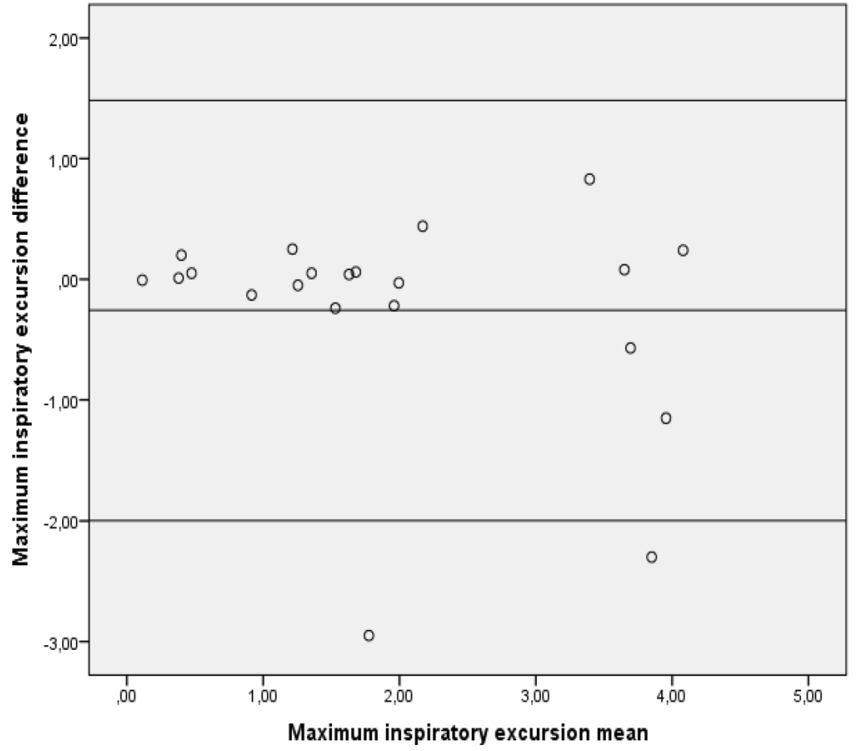

(b)

Fig. 3 a Bland-Altman graphics of tidal excursion. b Bland-Altman graphics of maximum inspiratory excursion

in measuring muscle thickness, the potential to overestimate diaphragm muscle thickness and an inability to discriminate between excursion resulting from extrinsic mechanical positive pressure and intrinsic diaphragm contractility [26-28]. BM ultrasound provides good anatomical view of the muscle and with its adjacent structures to measure thickness both at inspiration and expiration, a more detailed visualization of the diaphragm in two dimensions in comparison with MM and morphometry overcomes the limitations of displacement ambiguities by representing only active diaphragm contraction [26, 29-31]. According to Houston's study direct visualization of diaphragm and measuring its thickness by BM ultrasound provides a best method for detection of unilateral or bilateral paralysis in subjects with clinical suspicion of diaphragm dysfunction [32].

Diaphragm motion and thickness may be different from one location to the other; to avoid this limitation, it is essential to perform the ultrasound exam using identical 
Fig. 4 Measurements of diaphragm thickness with BM (a zoomed in appearance of the area in the circle in $\mathbf{b}$ ) and MM (b)



(a)

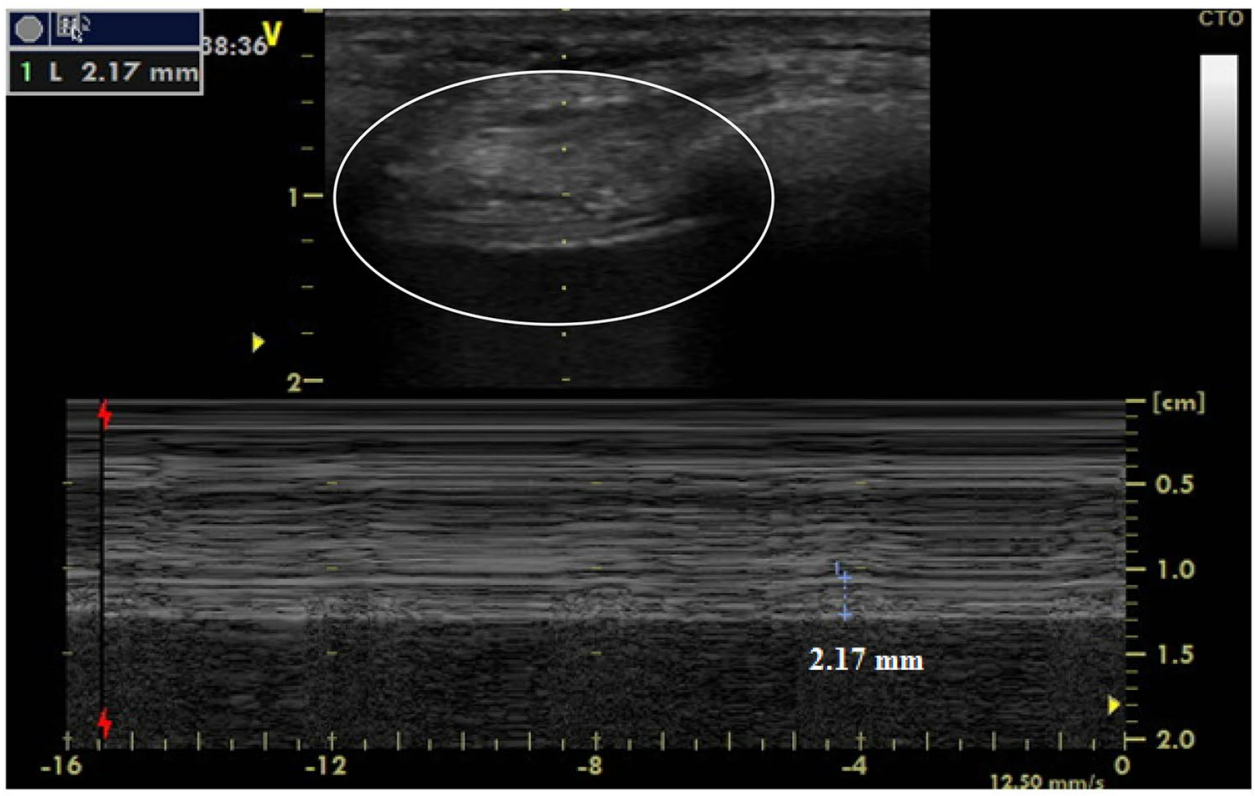

(b)

ultrasound beam position and direction. Especially motion variations are more pronounced for MM. The measurement is easy but there is a high risk that taking thickness measurements in different parts of the diaphragm during inspiration and expiration.

Sometimes diaphragm borders can not be detected clearly when its' thickness is measured with MM. In our study, we obviously observed in our nine subjects that, during MM recordings of diaphragm thickness diaphragm slided rigoriously under the MM cursor and we could not excluded this effect during our MM measurements even during tidal measurements. Probably for these reasons in our study we found significant disagreement between MM and BM measurements of diaphragm thickness during inspiration. In IVC measurement studies, this problem was documented very well in previous studies. For this reason it is recommended to measure the respiratory variability of IVC with BM instead of MM [33, 34]. In this regard, there are no studies on diaphragm, but there are IVC studies. Movement of the IVC occurs mediolaterally and craniocaudally during respirophasic ultrasound with collapse of the vessel occurring off axis from the true vertical. This has led to offer in methodological approaches to IVC measurement supporting $\mathrm{BM}$ and discouraging $\mathrm{MM}[12,35]$. 
Fig. 5 Measurements of diaphragm excursion with BM and $\mathrm{MM}$

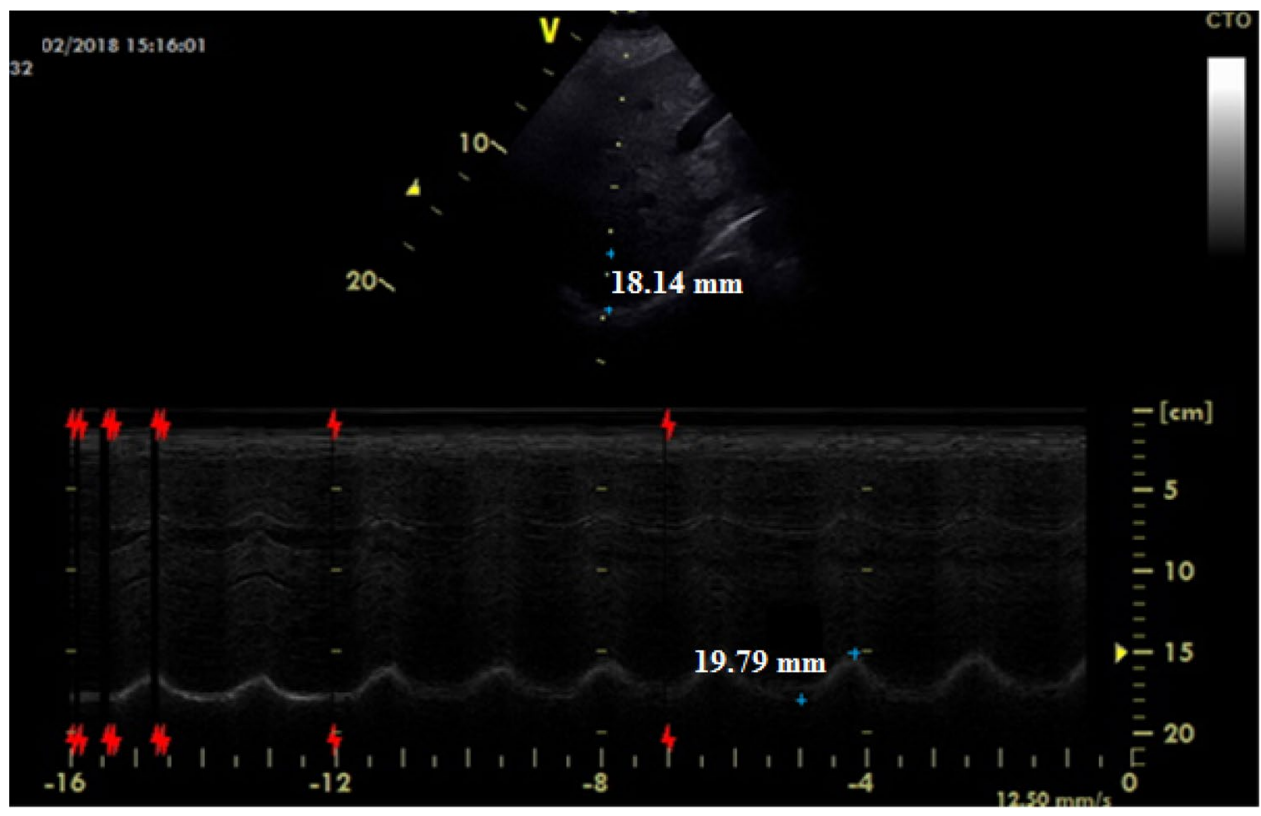

There is no standardized method to evaluate diaphragm thickness, thickening fraction and excursion. Results of our study suggest that there might be some small differences between BM and MM measurements of inspiratory diaphragm thickness.

Although the measurement of diaphragm inspiratory and expiratory thicknesses with BM can be seen as a logical solution in the repeated measurements, it is more difficult to do this and standardize the excursion measurements. The main reason is difficult to standardize the depth of subject's breathing (especially if intubated in intensive care). Secondly, with deep breathing, during the excursion the diaphragm domes not only move cranial and caudal, but also slide laterally. Thus, during the measurement with the MM, the diaphragm is continuously displaced and makes measurement very difficult from the same location.

\subsection{Limitations of the study}

The limitation of the study was that some of the subjects are intubated, some are not intubated and the number of intubated subjects was low and for this reason insidence of DD could not be evaluated in this important subgroup.

\subsection{Conclusion}

Results of this study suggest that except inspiratory diaphragm thickness all thickness and excursion measurements with $\mathrm{MM}$ and BM are very compatible with each other and incidence of DD measured by both modes were similar.

Acknowledgement This study was supported by the foundation of Gazi University Scientific Researche Projects (No: 01/2015-48).

\section{Compliance with ethical standards}

Conflict of interest The authors alone are responsible for the content and writing of the manuscript. The authors report no conflicts of interest.

\section{References}

1. Dubé BP, Dres M. Diaphragm dysfunction: diagnostic approaches and management strategies. J Clin Med. 2016;5:E113.

2. Sarwal A, Liu A, Cartwright MS, et al. Sonography for assessing dynamic diaphragm dysfunction in acute respiratory distress. J Ultrasound Med. 2015;34:1701-6.

3. Supinski GS, Callahan LA. Diaphragm weakness in mechanically ventilated critically ill patients. Crit Care. 2013;17:R120.

4. Dres M, Dube BP, Mayaux J, et al. Coexistence and impact of limb muscle and diaphragm weakness at time of liberation from mechanical ventilation in medical intensive care unit patients. Am J Respir Crit Care Med. 2017;195:57-66.

5. Dres M, Demoule A. Diaphragm dysfunction during weaning from mechanical ventilation: an underestimated phenomenon with clinical implications. Crit Care. 2018;22:73.

6. Demoule A, Jung B, Prodanovic H, et al. Diaphragm dysfunction on admission to the intensive care unit. Prevalence, risk factors, and prognostic impact-a prospective study. Am J Respir Crit Care Med. 2013;188:213-9.

7. Sferrazza Papa GF, Pellegrino GM, Di Marco F, et al. A review of the ultrasound assessment of diaphragmatic function in clinical practice. Respiration. 2016;91(5):403-11.

8. McCool FD, Tzelepis GE. Dysfunction of the diaphragm. N Engl J Med. 2012;366:932-42.

9. Boon AJ, O'Gorman C. Ultrasound in the assessment of respiration. J Clin Neurophysiol. 2016;33:112-9.

10. Dubé BP, Dres M, Mayaux J, et al. Ultrasound evaluation of diaphragm function in mechanically ventilated patients: comparison to phrenic stimulation and prognostic implications. Thorax. 2017;72:811-8. 
11. Spadaro S, Grasso S, Mauri T, et al. Can diaphragmatic ultrasonography performed during the T-tube trial predict weaning failure? The role of diaphragmatic rapid shallow breathing index. Crit Care. 2016;20(1):305.

12. Blehar DJ, Resop D, Chin B, et al. Inferior vena cava displacement during respirophasic ultrasound imaging. Crit Ultrasound J. 2012;4:18.

13. Mariani LF, Bedel J, Gros A, et al. Ultrasonography for screening and follow-up of diaphragmatic dysfunction in the ICU: a pilot study. J Intensiv Care Med. 2016;31:338-43.

14. Umbrello M, Formenti P. Ultrasonographic assessment of diaphragm function in critically ill subjects. Respir Care. 2016;61:542-55.

15. Boussuges A, Brégeon F, Blanc P, et al. Characteristics of the paralysed diaphragm studied by M-mode ultrasonography. Clin Physiol Funct Imaging. 2018;39:143-9.

16. Gursel G, Inci K, Alasgarova Z. Can diaphragm dysfunction be reliably evaluated with pocket-sized ultrasound devices in intensive care unit? Crit Care Res Pract. 2018. https://doi. org/10.1155/2018/5192647.

17. Skaarup SH, Løkke A, Laursen CB. The area method: a new method for ultrasound assessment of diaphragmatic movement. Crit Ultrasound J. 2018;10(1):15.

18. Brown C, Tseng SC, Mitchell K, et al. Body position affects ultrasonographic measurement of diaphragm contractility. Cardiopulm Phys Ther J. 2018;29:166-72.

19. Baria MR, Shahgholi L, Sorenson EJ, et al. B-mode ultrasound assessment of diaphragm structure and function in patients with COPD. Chest. 2014;146:680-5.

20. Khan MT, Munawar K, Hussain SW, et al. Comparing ultrasound-based diaphragmatic excursion with rapid shallow breathing index as a weaning predictor. Cureus. 2018;10:e3710.

21. Scarlata S, Mancini D, Laudisio A, et al. Reproducibility and clinical correlates of supine diaphragmatic motion measured by M-mode ultrasonography in healthy volunteers. Respiration. 2018;96:259-66.

22. Cohn D, Denditt JO, Eveloff S, et al. D Diaphragm thickening during inspiration. J Appl Physiol. 1997;83:291-6.

23. Lerolle N, Guerot E, Dimassi S, et al. Ultrasonographic diagnostic criterion for severe diaphragmatic dysfunction after cardiac surgery. Chest. 2009;135:401-7.

24. Kim WY, Suh HJ, Hong SB, et al. Diaphragm dysfunction assessed by ultrasonography: influence on weaning from mechanical ventilation. Crit Care Med. 2011;39:2627-30.

25. Vivier E, Mekontso Dessap A, Dimassi S, et al. Diaphragm ultrasonography to estimate the work of breathing during noninvasive ventilation. Intensiv Care Med. 2012;38:796-803.

26. Goligher EC, Laghi F, Detsky ME, et al. Measuring diaphragm thickness with ultrasound in mechanically ventilated patients: feasibility, reproducibility and validity. Intensiv Care Med. 2015;41(4):642-9.

27. Cohn D, Benditt JO, Eveloff S, McCool FD. Diaphragm thickening during inspiration. J Appl Physiol. 1997;83(1):291-6.

28. Wait JL, Nahormek PA, Yost WT, Rochester DP. Diaphragmatic thickness-lung volume relationship in vivo. J Appl Physiol. 1989;67(4):1560-8.

29. Boon AJ, Harper CJ, Ghahfarokhi LS, et al. Two-dimensional ultrasound imaging of the diaphragm: quantitative values in normal subjects. Muscle Nerve. 2013;47:884-9.

30. DiNino E, Gartman EJ, Sethi JM, McCool FD. Diaphragm ultrasound as a predictor of successful extubation from mechanical ventilation. Thorax. 2014;69(5):423-7.
31. Brown C, Tseng SC, Mitchell K, Roddey T. Body position affects ultrasonographic measurement of diaphragm contractility. Cardiopulm Phys Ther J. 2018;29(4):166-72.

32. Houston JG, Fleet M, Cowan MD, McMillan NC. Comparison of ultrasound with fluoroscopy in the assessment of suspected hemidiaphragmatic movement abnormality. Clin Radiol. 1995;50:95-8.

33. Finnerty NM, Panchal AR, Boulger C, et al. Inferior vena cava measurement with ultrasound: what is the best view and best mode? West J Emerg Med. 2017;18:496-501.

34. Levitov A, Frankel HL, Blaivas M, et al. Guidelines for the appropriate use of bedside cardiac ultrasonography in the evaluation of critically ill patients. Crit Care Med. 2016;44:1206-27.

35. Celebi Yamanoglu NG, Yamanoglu A, Parlak I, et al. The role of inferior vena cava diameter in volume status monitoring; the best sonographic measurement method? Am J Emerg Med. 2015;33:433-8.

36. Gottesman E, McCool FD. Ultrasound evaluation of the paralyzed diaphragm. Am J Respir Crit Care Med. 1997;155(5):1570-4.

37. Boussuges A, Gole Y, Blanc P. Diaphragmatic motion studied by m-mode ultrasonography: methods, reproducibility, and normal values. Chest. 2009;135(2):391-400.

38. Testa A, Soldati G, Giannuzzi R, et al. Ultrasound M-mode assessment of diaphragmatic kinetics by anterior transverse scanning in healthy subjects. Ultrasound Med Biol. 2011;37(1):44-52.

39. Voyvoda N, Yücel C, Karataş G, et al. An evaluation of diaphragmatic movements in hemiplegic patients. Br J Radiol. 2012;85(1012):411-4.

40. Carrillo-Esper R, Pérez-Calatayud ÁA, Arch-Tirado E, et al. Standardization of sonographic diaphragm thickness evaluations in healthy volunteers. Respir Care. 2016;61(7):920-4.

41. Laviola M, Priori R, D’Angelo MG, Aliverti A. Assessment of diaphragmatic thickness by ultrasonography in Duchenne muscular dystrophy (DMD) patients. PLoS ONE. 2018;13(7):e0200582.

42. Boccatonda A, Decorato V, Cocco G, et al. Ultrasound evaluation of diaphragmatic mobility in patients with idiopathic lung fibrosis: a pilot study. Multidiscip Respir Med. 2019;14:1.

43. Zhu Z, Li J, Yang D, et al. Ultrasonography of diaphragm can predict pulmonary function in spinal cord injury patients: a pilot case-control study. Med Sci Monit. 2019;25:5369-74.

44. Fayssoil A, Nguyen LS, Ogna A, et al. Diaphragm sniff ultrasound: normal values, relationship with sniff nasal pressure and accuracy for predicting respiratory involvement in patients with neuromuscular disorders. PLoS ONE. 2019;14(4):e0214288.

45. Spadaro S, Grasso S, Dres M, et al. Point of care ultrasound to identify diaphragmatic dysfunction after thoracic surgery. Anesthesiology. 2019;131(2):266-78.

46. Schepens T, Verbrugghe W, Dams K, et al. The course of diaphragm atrophy in ventilated patients assessed with ultrasound: a longitudinal cohort study. Crit Care. 2015;19:422.

47. Goligher EC, Fan E, Herridge MS, et al. Evolution of diaphragm thickness during mechanical ventilation. Impact of inspiratory effort. Am J Respir Crit Care Med. 2015;192:1080-8.

48. Yoo J-W, Lee SJ, Lee JD, Kim HC. Comparison of clinical utility between diaphragm excursion and thickening change using ultrasonography to predict extubation success. Korean J Intern Med. 2018;33(2):331-9.

49. Theerawit P, Eksombatchai D, Sutherasan Y, et al. Diaphragmatic parameters by ultrasonography for predicting weaning outcomes. BMC Pulm Med. 2018;18(1):175. 
50. Pirompanich P, Romasaiyut S. Use of diaphragm thickening fraction combined with rapid shallow breathing index from mechanical ventilator in medical patients. J Intensiv Care. 2018;6:6.

51. Vivier E, Muller M, Putegnat JB, et al. Inability of diaphragm ultrasound to predict extubation failure: a multicenter study. Chest. 2019;155(6):1131-9.

52. Rittayamai N, Hemvimon S, Chierakul N. The evolution of diaphragm activity and function determined by ultrasound during spontaneous breathing trials. J Crit Care. 2019;51:133-8.
Publisher's Note Springer Nature remains neutral with regard to jurisdictional claims in published maps and institutional affiliations. 